\title{
Modulation of la EPSP Amplitude: The Effects of Chronic Synaptic Inactivity
}

\author{
Craig B. Webb and Timothy C. Cope \\ Physiology Department, Hahnemann University, Philadelphia, Pennsylvania 19107
}

In this study, we test the hypothesis that monosynaptic connections between la afferents and spinal motoneurons are strengthened by chronic disuse. Impulse activity along the medial gastrocnemius (MG) nerve was blocked for 2 weeks using TTX delivered by an osmotic minipump to a Silastic cuff placed around the nerve. The duration and specificity of this block were confirmed by chronic EMG recordings from several triceps surae muscles. The effect of TTX-induced inactivity of presynaptic elements on EPSP amplitude was distinguished from the effect of treating the postsynaptic target by comparing the results from heteronymous synaptic connections, where only one or the other element was treated. After 2 weeks of synaptic inactivity, the heteronymous EPSPs generated by MG la afferents in lateral gastrocnemius/soleus (LG-Sol) motoneurons were significantly ( $p<$ 0.005 ) larger than control values ( $48 \%$ ). Sample differences in rheobase current and half-afterhyperpolarization, both of which may covary with EPSP amplitude, did not account for the differences between groups. Segregation of the two samples of motoneurons by rheobase current identified the increase as being confined to those LG-Sol cells whose rheobase fell below $10 \mathrm{nA}$. In addition, EPSPs generated by untreated LG-Sol la afferents in treated MG motoneurons were significantly enhanced $(39 \%, p<0.05)$. Thus, TTX treatment of either presynaptic or postsynaptic elements increases synaptic strength. This increase in monosynaptic EPSP amplitude following TTX-induced inactivity may reflect an alteration intrinsic to the la afferent to motoneuron synapse, but influences from extrinsic sources cannot be discounted.

There are relatively few direct examples from the mammalian CNS in vivo showing that synaptic strength can be persistently altered by changes in synaptic activity (e.g., Bliss and Lomo, 1973; Tsukahara and Fuji, 1981). In the cat spinal cord, longterm changes in EPSPs have been measured under a variety of conditions at the synaptic connections made by group Ia muscle spindle afferents with $\alpha$-motoneurons (Mendell, 1984). Perhaps the strongest case for the influence of use on the strength of normally active Ia afferent synapses comes from the studies of Kuno and coworkers. They blocked impulses in sensory axons from reaching the synaptic terminals in the spinal cord by con-

Received June 10, 1991; revised Aug. 20, 1991; accepted Aug. 30, 1991.

This research was supported by NIH Grant NS21023. We gratefully acknowlcdge B. D. Clark for his help in preparation of the manuscript.

Correspondence should be addressed to Timothy C. Cope, Physiology Department, Hahnemann University, Broad \& Vine, Mail Stop 409, Philadelphia, PA 19107.

Copyright $(\mathcal{C} 1992$ Society for Neuroscience $0270-6474 / 92 / 120338-07 \$ 05.00 / 0$ tinuously infusing peripheral nerves with TTX. The EPSPs recorded intracellularly from motoneurons contacted by axons of TTX-treated Ia afferents in both cat (Gallego et al., 1979) and rat (Manabe et al., 1989) were significantly larger soon after chronic TTX treatment was discontinued.

These studies show that a central synapse might respond to prolonged inactivity by increasing transmission strength. However, that increase might also have been brought about secondary to, or possibly independent of, the disuse of Ia afferents. In addition to blocking the single motor nerve, Kuno and coworkers also extensively deafferented the motoneuron pool, either by denervating all but three muscles in the hind limb (Gallego et al., 1979) or by blocking the entire sciatic nerve with TTX (Manabe et al., 1989). Given that the strength of transmission from intact Ia afferents onto motoneurons increases after partial denervation of motoneuron pools, such as that produced by sectioning the spinal cord (Nelson and Mendell, 1979) or dorsal root afferents (Eccles and McIntyre, 1951), the extensive deafferentation used in the TTX studies may itself have had a significant effect on the resultant EPSP amplitudes.

Another aspect of the TTX studies that could confound the interpretation that presynaptic inactivity alone enhances EPSP size is that the most pronounced changes were seen in cases where the postsynaptic element had also been treated with TTX. For example, in the Gallego et al. (1979) study where EPSPs generated by both treated medial gastrocnemius (MG) and untreated lateral gastrocnemius/soleus (LG-Sol) afferents could be measured, the greatest change in EPSP size was noted at homonymous connections with treated MG moloneurons. Thus, it may be that both presynaptic and postsynaptic treatments are contributing, independently, to the increase in EPSP amplitude at these synapses.

The degree of enhancement of the aggregate EPSP following disuse may be influenced by characteristics of the postsynaptic target. For example, both single-fiber EPSP amplitude as well as changes in that amplitude in response to high-frequency activation of the afferent vary with the rheobase of the motoneuron from which they are measured (Collins et al., 1984, 1986). Following acute spinal cord transection, EPSP enlargement is greatest for type $S$ motoneurons (Cope et al., 1980). Using rheobase current to classify postsynaptic neurons, we intended to determine whether the synaptic response to a period of afferent inactivity is uniform among the connections found in the motoneuron pool.

The hypothesis that central synapses might be strengthened by inactivity runs counter to numerous investigations since the landmark work of Hebb (1949). For example, Fields et al. (1991) recently reported that for neurons cultured from mouse spinal cord, synapses made by unstimulated presynaptic cells were not as strong as those made by stimulated cells. That finding is 
consistent with Stent's (1973) extension of the Hebbian concept, namely that asynchronous activity in pre- and postsynaptic elements of a synapse should weaken transmission. If that principle were operating after TTX blockade of impulses in peripheral nerves, one would predict a decrease rather than the observed increase in EPSP size, since centrally driven motoneuron activity continues (Stein et al., 1980) while impulses initiated in muscle fail to arrive at Ia synapses in the spinal cord.

This study was designed to test the hypothesis that Ia synapses respond to chronic disuse with a significant increase in strength. The nerve supplying only one hind limb muscle was chronically treated with TTX while the rest of the nerve supply to the limb was undisturbed. After treatment, EPSPs were measured intracellularly. The divergence of Ia afferents to synergistic motoneuron pools allowed study of EPSPs generated at heteronymous monosynaptic connections involving either treated Ia afferents or treatcd motoncurons. Sclected motoncuron propertics were measured so that we could determine whether disuse-induced changes vary systematically across the motoneuron pool.

Preliminary results of this work were reported in abstract form (Webb and Cope, 1990).

\section{Materials and Methods}

Chronic preparation and study. Sterile surgical procedure was used to implant electrodes and an infusion apparatus subcutaneously in the left hind limb of adult mongrel cats of either sex. Cats were anesthetized before and throughout surgery by a gaseous mixture of halothane (1$2 \%$ ) in oxygen ( 2 liters $/ \mathrm{min}$ ). An incision (about $8 \mathrm{~cm}$ ) was made in the skin over the popliteal fossa to expose the nerve to the MG muscle and the proximal portions of the MG and lateral gastrocnemius (LG) muscles. The MG nerve was gently separated in continuity from surrounding connective tissue over about $2 \mathrm{~cm}$ just proximal to its entry into the muscle. A slit Silastic cuff (inner diameter range, 0.132-0.078 mm) was gently fit around the dissected MG nerve. Two loops of suture were tied around the outside of the cuff to hold it closed. The cuff was filled with solution injected through a Silastic "feeder" tube $(0.02 \mathrm{~mm}$ i.d.) glued at one end into the lumen of the cuff. The other end of the feeder tube was led to a midthigh position and connected to an osmotic minipump (Alza model 2002) previously filled with $0.25 \mathrm{ml}$ of solution. The minipump was anchored by suture to subcutaneous connective tissue. The cuff and pump were filled with TTX $(0.25 \mathrm{mg} / \mathrm{ml}, \mathrm{pH} 7)$ in saline (TTX group). Initial studies demonstrated that saline substituted for TTX solution neither blocked nerve conduction nor evoked any enhancement of EPSP amplitude. In four cats, the MG nerve was crushed by fine jeweler's forceps in the region of the Silastic cuff when the cuff was installed (TTX/CRSH group). Thin Dacron patches holding bipolar electrodes $(125 \mu \mathrm{m}$ diameter silver wire, terminal $5 \mathrm{~mm}$ bared and separated by $3-6 \mathrm{~mm}$ ) were sewn through epimysium to the surfaces of the MG and LG muscles. The wire leads of these electrodes, together with a free-floating ground wire, were directed subcutaneously to a small incision in the skin at the hip and attached to a six pin connector that was then sewn to the skin at that position. The popliteal incision was closed in layers, and topical antibiotic was applied to incision sites. Cats were then returned to their cages and closely observed during recovery from surgery. Antibiotic given orally the day before surgery was continued for 2-3 d afterward.

The day after surgery and on several occasions prior to the terminal experiment, cats were brought into the laboratory for a brief recording session. The indwelling electrodes were connected to AC amplifiers through a braided cable plugged into the pin conncetor. Elcctromyographic (EMG) records from MG and LG muscles were inspected on an oscilloscope screen while the cat moved and supported weight on its left hind limb. In five cats from the TTX group, as well as in the four from the TTX/CRSH group, EMG activity was prominent in the LG muscle and absent or greatly reduced in the MG muscle (Fig. 1). Records from the saline control group and from cats in which TTX failed to block impulse traffic demonstrated that coactivation of the MG and LG muscles could be expected under the conditions used to test their activity (see also Rassmussen et al., 1978). All cats used the treated limb without difficulty (all exhibited a digitigrade stance) and responded to gentle
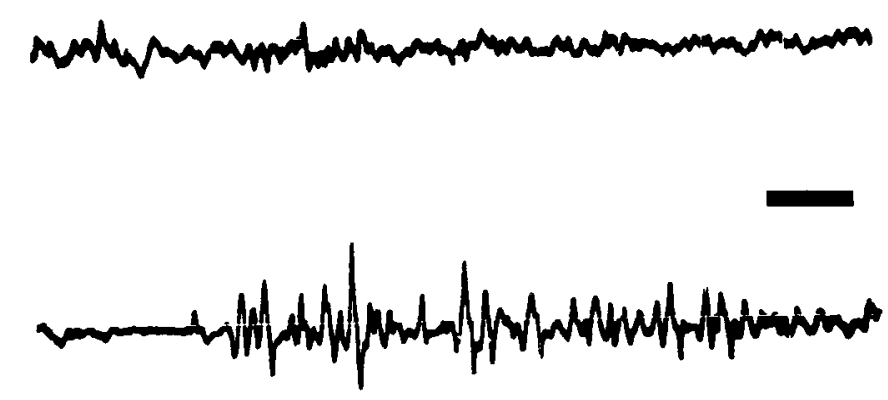

Figure 1. Simultaneous EMG records from MG and LG muscles during TTX blockade. Top trace, oscilloscope record of EMG activity from the MG muscle. Bottom trace, record of EMG activity from the LG muscle, taken at the same gain. Such records were used to confirm the duration and specificity of TTX blockade of the MG nerve. Calibration, $10 \mathrm{msec}$.

manual stimulation of skin overlying the calf muscles and paw. These observations demonstrated that our treatment paradigm was effective in blocking nervous activity without dramatically altering whole limb motor or sensory systems.

When EMG activity was observed in the LG but not in the MG muscle, we inferred that impulse activity in the MG nerve was blocked at the cuff and that conduction in the nearby LG nerve was not affected by the treatment. In all of those cases, the selective TIX conduction block remained in effect up to the time of the terminal experiment. Cats were discarded from further study when conduction in the MG nerve either was not blocked by TTX, occurring when the nerve cuff was displaced, or was not tested because EMG electrodes were dislodged before recording.

Terminal experiment. The chronically treated cats as well as eight untreated cats, all adults of either sex, were studied in terminal experiments. The procedures used for recording synaptic potentials from spinal motoneurons were similar to those described previously (Cope et al., 1988). Anesthesia of the cats was induced $(40 \mathrm{mg} / \mathrm{kg}$ sodium pentobarbital, i.p.) and maintained (intravenous infusion) throughout the experiment as required to suppress withdrawal reflexes completely. Blood pressure, end-tidal $\mathrm{CO}_{2}$, and body temperature were continuously monitored. Spinal cord segments $\mathrm{L}_{4}-\mathrm{L}_{7}$ were exposed by laminectomy. The combined LG-Sol nerve supplying the lateral gastrocnemius and soleus muscles and the MG nerve were isolated in the left hind limb for electrical stimulation. All other nerves in the left hind limb were cut. Exposed tissues were bathed in mineral oil maintained at $37^{\circ} \mathrm{C}$ by radiant heat.

Intracellular potentials were recorded from motoneurons using glass pipettes pulled to resistances between 10 and $20 \mathrm{M} \Omega$ and filled with 2 $M$ potassium acetate. MG and LG-Sol motoneurons penetrated by these electrodes were identified by the antidromic action potentials they generated upon electrical stimulation ( $1 \mathrm{pps}$ rate, $0.02 \mathrm{msec}$ duration) of their peripheral nerves. No attempt was made to distinguish LG and Sol motoneurons. It is likely, however, that few Sol motoneurons were sampled since most of the Sol motor nucleus is found caudal to the rostral extent of the $L_{7}$ dorsal root entry zone (Romanes, 1951) where most cells responding to LG-Sol nerve stimulation were penetrated. Motoneurons generating action potentials in excess of $60 \mathrm{mV}$ were accepted for further study according to the following protocol. Monosynaptic EPSPs were generated by electrical stimulation of peripheral nerves at 1.25 pps. The MG nerve was stimulated just proximal to the cuff site, since the TTX blockade of conduction did not dissipate for many hours after removal of the cuff during the terminal experiment. This was expected because preliminary experiments showed that re peated washing of the nerve with warm saline for many hours was required to reverse a complete block produced under these conditions. Stimulus strength was gradually increased to a level that produced the maximum amplitude monosynaptic EPSP. Orthodromic potentials recorded by a silver ball electrode placed gently among the $\mathrm{L}_{7} / \mathrm{S}_{1}$ dorsal roots showed that this stimulus strength was typically about $2 \times$ group I threshold (cf. Burke et al., 1976).

Additional motoneuron electrical properties were measured. Rheobase current was measured as the amount of depolarizing current, injected as a $50 \mathrm{msec}$ square pulse, that just brought the motoneuron to 


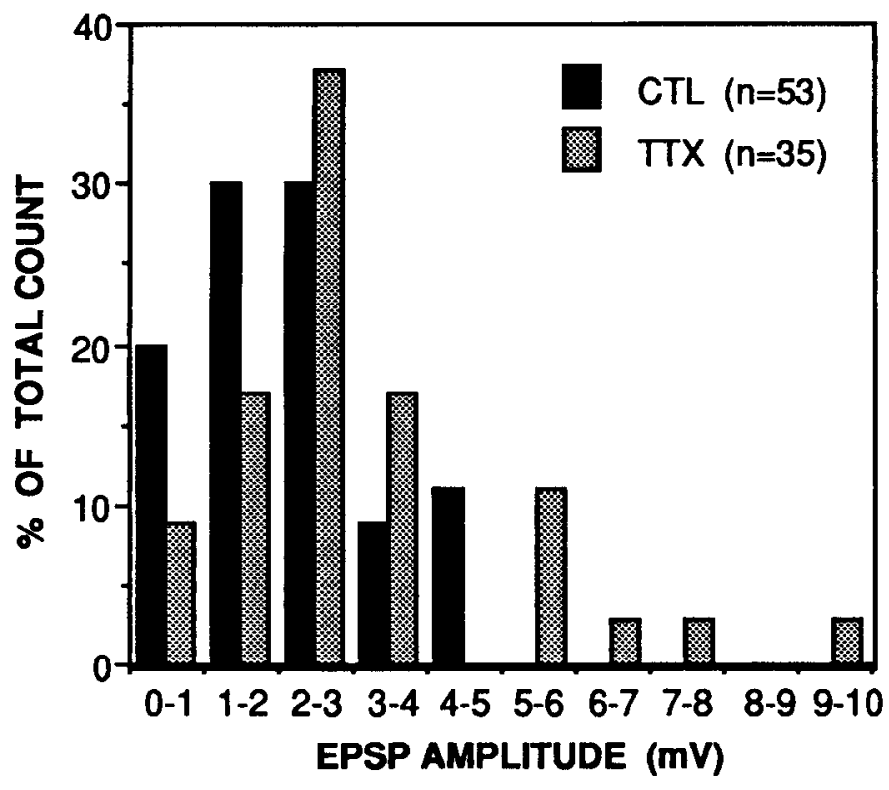

Figure 2. Frequency histogram of monosynaptic EPSP amplitudes recorded from LG-Sol motoneurons. These potentials were generated by stimulation of the MG nerve at a strength sufficient to give the maximum aggrcgatc EPSP. Solid bars, untrcatcd control (CTL) group; shaded bars, TTX-treated group. The mean EPSP amplitude following TTX treatment $(3.1 \mathrm{mV})$ is significantly greater $(p<0.005)$ than the control value $(2.1 \mathrm{mV})$.

threshold. We also measured the half-decay time of the afterhyperpolarization (AHP) following action potentials initiated by brief intracellular suprathreshold pulses of current $(0.5 \mathrm{msec})$. Finally, resting membrane potential was determined from the voltage deffection measured upon removing the microelectrode from the motoneuron. Data were accepted only when resting potential remained steady throughout recording and exceeded $-60 \mathrm{mV}$ when the electrode was withdrawn from the motoneuron. Failure to meet those criteria and difficulty in passing current through the microelectrode account for some fragmentation in the data set of motoneuron measures. All records were digitized (12 bit resolution, $40 \mathrm{kHz}$ ) and stored by computer for later analysis. Records of EPSPs and of action potentials were stored as the averages of 10 stimulus-triggered sweeps.

\section{Results}

Properties of motoneurons and composite monosynaptic EPSPs are presented in Table 1 . By listing data separately for $M G$ and LG-Sol motoneurons, the table segregates heteronymous EPSPs according to whether the afferent or motoneuron element of the monosynaptic connection was treated.

\section{EPSPs generated by TTX-treated afferents}

Monosynaptic EPSPs generated in LG-Sol motoneurons by TTXtreated MG afferents were on average $48 \%$ larger than those produced by untreated MG afferents (Table 1). Figure 2 shows that the larger mean resulted from an expansion of the range of the amplitude distribution for EPSPs in the TTX group. In addition to some unusually large EPSPs, there were fewer than normal small ones. Thus, the value delimiting the lower quartile of the TTX group $(2.05 \mathrm{mV})$ approximated the median value for EPSPs in the control group $(2.00 \mathrm{mV})$. In the TTX/CRSH group, there was a significant reduction in the amplitude of EPSPs generated by MG afferents in the LG-Sol motoneurons. EPSP rise time, motoneuron rheobase, and AHP half-decay time for LG-Sol cells in TTX-treated and TTX/CRSH groups were not significantly different from the untreated controls.

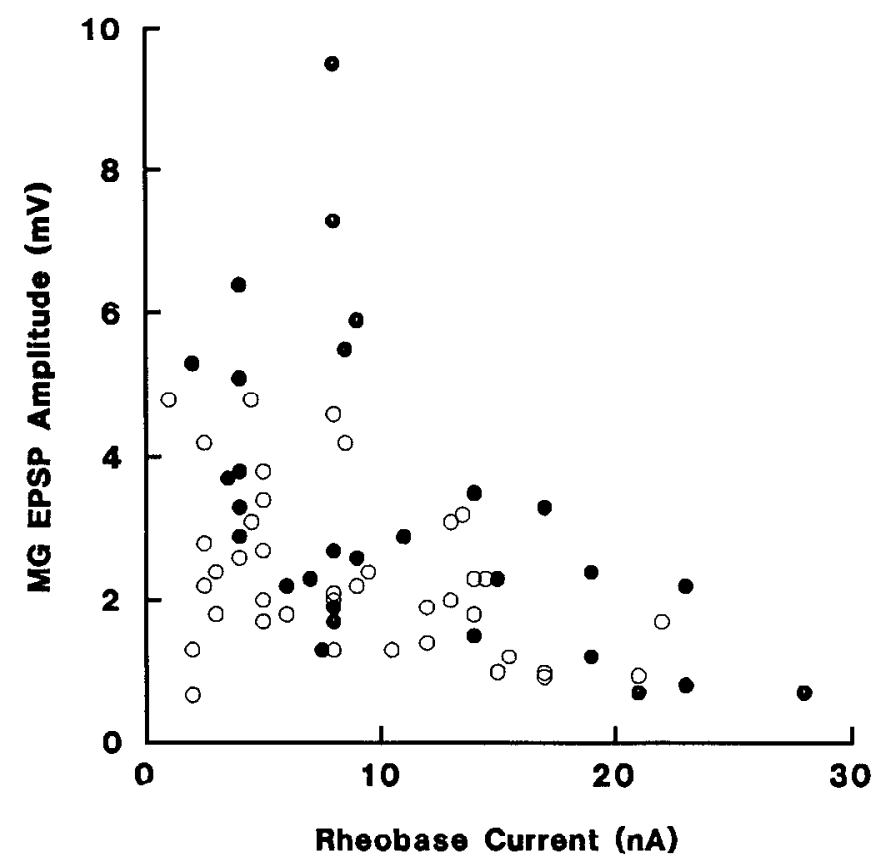

Figure 3. Plot of relationship between motoneuron rheobase current and EPSP amplitude. Monosynaptic EPSPs were recorded in LG-Sol motoneurons following stimulation of the MG nerve. Open circles, EPSP amplitude in untreated control animals. Solid circles. EPSP amplitude from animals whose MG nerve had been treated with TTX for 2 weeks.

The relationship between EPSP size and rheobase is shown in Figure 3. Motoneurons with relatively low rheobases generated EPSPs covering a wide range in size, including the largest EPSPs recorded. Only small EPSPs were observed in cells near the other end of the rheobase scale. This tendency, reported earlier by Collins et al. (1984) for EPSPs produced by single Ia afferents in motoneurons, was found here for composite EPSPs generated in LG-Sol motoneurons by untreated and TTX-treated MG afferents. The slopes of the linear regression of the log of EPSP amplitude on rheobase were significantly different from zero $(p<0.01)$ for both untreated $(r=0.54)$ and TTX-treated $(r=0.66)$ groups. Since the regressions for the two groups were not significantly different in slope $(p>0.05)$, we performed an analysis of covariance. This analysis demonstrated that the group difference in EPSP size remained significant $(p<0.005)$ even after adjusting for rheobase. Statistical adjustment for AHP halfdecay time was not made, because the linear regression of log EPSP amplitude on that parameter was not significant in the untreated control group $(r=0.08 ; p<0.10)$.

Because much of the variation in EPSP amplitude (Burke et al., 1976) has been related to motoneuron type [as part of type $\mathrm{S}$ (slow) and multiple type $\mathrm{F}$ (fast) motor units distinguished by the contractile speed and endurance of their muscle component], it is important to establish that the distribution of types is not different between samples. We used rheobase current and AHP half-decay time as predictors of motoneuron type for that purpose. Motoneurons were identified as type $\mathrm{S}$ when, for rheobase, values fell below $7.7 \mathrm{nA}$ or, for AHP half-decay time, values exceeded $30 \mathrm{msec}$ (Zengel et al., 1985). The fraction of LG-Sol motoneurons classified as type $S$ by either criterion was, for the TTX-treated group, equal to or less than the fraction classified as type $S$ in the untreated control group. It follows that the larger size of EPSPs generated by TTX-treated MG afferents was not 
due to sampling a greater fraction of type $\mathrm{S}$ motoneurons from that group compared to control. A similar conclusion can be drawn when using AHP half-decay time to determine the fraction of type S motoneurons in the untreated and TTX-treated groups of MG cells. Munson et al. (1985) found that MG motoncuron AHP half-decay time was unaffected by TTX treatment but that rheobase decreased significantly. Consistent with this finding, an unusually large percentage (47\%) of the motoneurons from our TTX-treated group would be classified as type $\mathrm{S}$ based solely on their rheobase.

The size of EPSPs generated by TTX-treated afferents seemed to be exaggerated among low-rheobase motoneurons (Fig. 3). To test that impression, we compared EPSPs from LG-Sol motoneurons whose rheobases fell above and below $10 \mathrm{nA}$. We selected that value without regard to any division of the motoneuron pool based on type; we simply wished to investigate a feature of the data that is evident in Figure 3. That cutoff value is, however, similar to the one used to separate type $S$ from type F motoneurons (see above). Figure 4 shows that EPSPs from LG-Sol motoneurons were significantly different in TTXtreated versus untreated groups only for the low-rheobase cells. Thus, the significant increase found in pooled data (Table 1) was produced by a selective increase in size of EPSPs from lowrheobase, predominantly type $\mathrm{S}$, motoneurons.

\section{TTX treatment of the postsynaptic axon}

The amplitude of EPSPs generated by LG-Sol afferents in MG motoneurons was significantly larger in neurons whose axons had been treated with TTX than in untreated neurons (Table 1). The amplitude of heteronymous EPSPs sampled from TTXtreated motoneurons tended toward larger than normal values (Fig. 5). The interquartile ranges (25-75\%) of the treated and untreated groups were similar, $1.3 \mathrm{mV}$ and $1.1 \mathrm{mV}$, but only $22 \%$ of the EPSPs from TTX-treated motoneurons were smaller than the median value $(1.65 \mathrm{mV})$ for EPSPs measured in untreated MG motoneurons. This shift of the distribution resulted in the significant group difference in mean EPSP size shown in Table 1. Following TTX treatment of the MG nerve, AHP halfdecay time of $M G$ motoneurons was unchanged. In addition, although EPSP rise time tended to be longer and rheobase small-

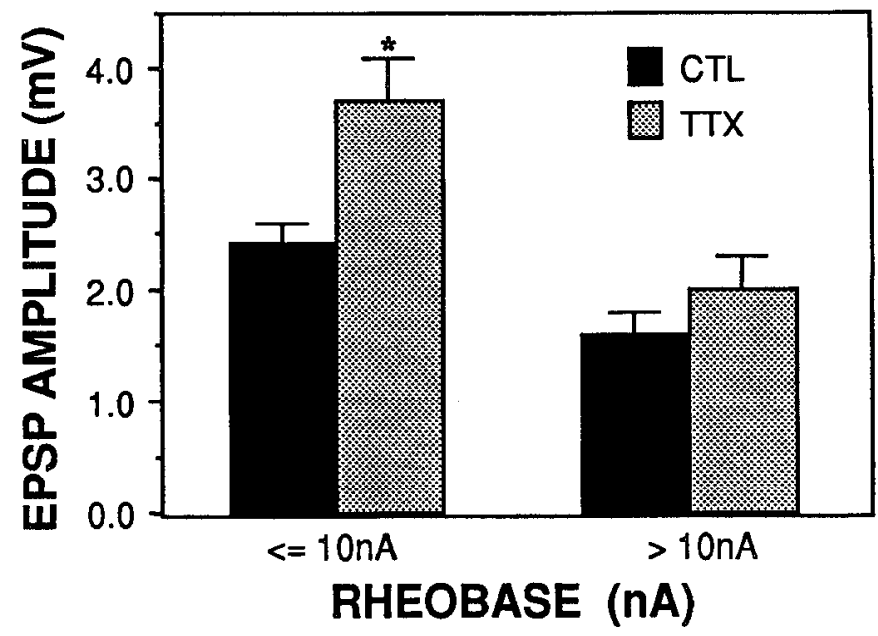

Figure 4. Mean EPSP amplitude for LG-Sol motoneurons grouped according to rheobase. Monosynaptic EPSPs were recorded from LGSol motoneurons following stimulation of MG Ia afferents. Motoneurons are divided into two groups: those with rheobase less than or equal to $10 \mathrm{nA}$, and those with values greater than $10 \mathrm{nA}$. Solid bars, untreated control data $(C T L)$ from acute experiments; shaded bars, TTX-treated group. EPSP amplitude following MG afferent inactivity $(3.7 \mathrm{mV})$ was found to be significantly greater $(*, p<0.005)$ than control values $(2.4$ $\mathrm{mV}$ ) only for those LG-Sol cells with a lower rheobase. Error bars represent $\mathrm{SE}$.

er in these cells, the differences were not significant (Table 1). The tendency toward smaller rheobase values in the TTX-treated MG motoneurons does not explain the increase in EPSP amplitude for this group, since EPSPs were significantly enlarged $(p<0.05)$ even among high-rheobase MG cells (rheobase $>10$ $\mathrm{nA})$.

\section{$T T X$ treatment and nerve injury}

Injury to the nerve in the TTX-treatment groups could not be assessed in our experiments because TTX blockade of action potentials persisted until the terminal experiment (see Materials and Methods). To assess the potential effect of nerve injury on the TTX results, we studied a group of cats in which MG nerves were infused with TTX and also completely crushed. Composite

Table 1. Properties of motoneurons and composite monosynaptic EPSPs produced by heteronymous group Ia afferents

LG-Sol

motoneurons

\begin{tabular}{lllll}
$\begin{array}{l}\text { MG nerve } \\
\text { treatment }\end{array}$ & $\begin{array}{l}\text { MG EPSP } \\
\text { amplitude }(\mathrm{mV})\end{array}$ & $\begin{array}{l}\text { MG EPSP } \\
\text { rise time }(\mathrm{msec})\end{array}$ & $\begin{array}{l}\text { Rheobase } \\
\text { current (nA) }\end{array}$ & $\begin{array}{l}\text { AHP half-decay } \\
\text { time (msec) }\end{array}$ \\
\hline Untreated & $2.1 \pm 0.15(53)$ & $0.73 \pm 0.03(53)$ & $10.0 \pm 1.2(42)$ & $32.4 \pm 2.7(39)$ \\
TTX & $3.1 \pm 0.32(35)^{* *}$ & $0.72 \pm 0.03(34)$ & $10.9 \pm 1.2(29)$ & $26.6 \pm 2.2(30)$ \\
TTX/CRSH & $1.2 \pm 0.11(56)^{* *}$ & $0.71 \pm 0.03(46)$ & $9.0 \pm 0.8(47)$ & $25.5 \pm 1.3(42)$ \\
MG motoneurons & & & & \\
\hline MG nerve & LG-Sol EPSP & LG-Sol EPSP & Rheobase & AHP half-decay \\
treatment & amplitude (mV) & rise time (msec) & current (nA) & time (msec) \\
\hline Untreated & $1.8 \pm 0.18(38)$ & $0.76 \pm 0.06(37)$ & $10.2 \pm 1.3(33)$ & $31.3 \pm 2.8(27)$ \\
TTX & $2.5 \pm 0.29(18)^{*}$ & $0.91 \pm 0.11(18)$ & $7.0 \pm 1.3(17)$ & $30.6 \pm 3.1(17)$ \\
TTX/CRSH & $0.7 \pm 0.12(27)^{* *}$ & $0.73 \pm 0.06(17)$ & $5.3 \pm 0.8(26)^{*}$ & $26.2 \pm 1.9(18)$
\end{tabular}

Data from LG-Sol and MG motoneurons are presented separately for groups in which MG peripheral nerve was untreated or treated by either TTX or by TTX/CRSH. Values are group means \pm SEM with number of data points in parentheses. ${ }^{*}, p<0.05 ;{ }^{* *}, p<0.005$ (Mann-Whitney $U$ test) relative to untreated group. 


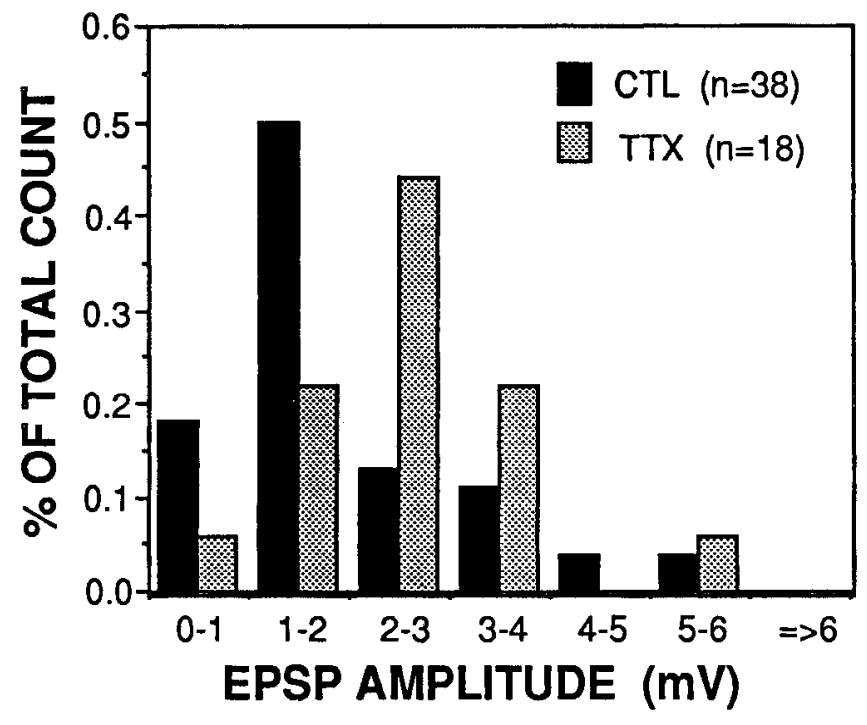

Figure 5. Frequency histogram of monosynaptic EPSPs recorded from MG motoneurons. EPSPs were generated by stimulation of the LG-Sol nerve at strength sufficient to generate the maximum aggregate EPSP. Solid bars, untreated control (CTL) data from acute experiments; shaded bars, TTX-treated group. A significant increase $(39 \%, p<0.05)$ in EPSP amplitude was measured in MG motoneurons whose axons had been treated.

EPSPs were significantly reduced in amplitude when either the afferents or the motoneurons were treated by TTX combined with crush (Table 1). Also, as expected (Foehring et al., 1986; Pinter and Vanden Noven, 1989), if a motoneuron's axon had been damaged, that cell's rheobase current was reduced (Table 1). Thus, although it was possible that unintentional damage of the TTX-treated nerves affected the parameters measured from that group, the injury would have diminished EPSP size, and therefore our measures would underestimate the increase in EPSP size due to TTX treatment alone.

\section{Discussion}

The fundamental finding of this study, that Ia EPSPs were enlarged after TTX treatment of a peripheral nerve, is comparable to earlier descriptions from Kuno's laboratory (see introductory remarks). Inactivity of Ia synapses may be a central factor in both studies. Unlike earlier work, the EPSP enhancement found here was not associated with whole limb denervation and was not, therefore, secondary to the substantial synaptic changes produced by widespread segmental deafferentation. EPSPs were significantly larger than normal at monosynaptic connections where only the presynaptic elements were treated with TTX. That finding supports the hypothesis that synaptic strength is responsive to presynaptic activity levels. Although Gallego et al. (1979) arrived at a similar conclusion, they found a presynaptic effect only when EPSPs generated by treated versus untreated Ia afferents were compared in the same motoneuron, and the sensitivity of their analysis has been questioned (Burke, 1984). In addition to the changes seen following presynaptic TTX treatment, we also found that untreated LG-Sol afferents produced enlarged EPSPs in TTX-treated MG motoneurons. Finally, we made the novel observation that the effect of silencing Ia afferents on synaptic strength was related to the rheobase current of the postsynaptic cell; increases in EPSP size were restricted to synapses made with the most excitable motoneurons.
The variation in size of group Ia EPSPs within the gastrocnemius motoneuron pool (Fig. 3; Burke, 1968; Burke et al., 1976) may lead to significant differences in EPSPs between two groups of motoneurons if the samples of cells are not comparable. We addressed this issue first by verifying that the samples from the untreated and TTX-treated groups were similar. Mean rheobase and AHP half-decay time were not significantly different between the untreated and TTX-treated conditions for either LG-Sol or MG motoneurons, and the slight group differences for rheobase in particular seemed unable to account for the group differences in EPSP size. Additionally, we found that in no case was a difference in sample mean EPSP amplitudes explained by a difference in the frequencies of motor unit types between experimental groups. Together, these observations minimize the chance that any bias in the sampling accounts for the significant difference in mean EPSP amplitudes.

The increase in EPSP size measured here probably reflects increased efficacy at synapses made between Ia afferents and motoneurons. Because the earliest response of the motoneuron to heteronymous group I electrical stimulation is generated by Ia fibers, the rise and peak of the Ia EPSP are largely uncontaminated by other stimulus-evoked responses. Tonic activity in spinal circuits outside the Ia afferent-motoneuron connection could conceivably influence EPSP size, but that activity would have been greatly reduced by our use of complete limb denervation and barbiturate anesthesia in the terminal experiment.

In the spinal cord, it has been difficult to distinguish activity, per se, as a stimulus for synaptic modification because of uncertainty about how afferent activity is changed after experimental manipulations such as muscle tenotomy, limb immobilization, or removal of synergistic muscles (for discussion, see Eccles, 1964; Mayer et al., 1981; Mendell, 1984). Our use of TTX on heteronymous spinal circuitry has helped to focus the experimental manipulation on inactivity; both widespread denervation of spinal segments as well as direct TTX treatment of motoneurons are eliminated as factors that might enhance synaptic transmission. It seems plausible, then, that our finding of enlarged Ia EPSPs following suppression of central synaptic transmission results from a dependency of strength on activity at those synapses. This interpretation must be guarded, however, in recognition of how difficult it is to establish a cause and effect relationship between use and strength at any synapse within the complex circuitry of the CNS.

The increase in EPSP amplitude associated with afferent inactivity has no parallel that we are aware of and runs counter to the commonly held view that synapses are strengthened by increased activity or synchronized neuronal firing (Hebb, 1949). One would not anticipate that the reduction in synchrony produced by silencing afferents while motoneurons continued to fire (despite axonal treatment with TTX; Stein et al., 1980) would stimulate EPSP enlargement, but that interpretation is consistent with our findings. We cannot extrapolate a description of the dependence of synaptic strength over a comprehensive range of activity levels, and it may be that the silencing of afferent synapses is not a simple linear extension of the reduced or asynchronous afferent activity associated with EPSP attenuation in the hippocampus (Lynch et al., 1977; Levy and Steward, 1979; Stanton and Sejnowski, 1989). Even so, the association of Ia EPSP enlargement with Ia afferent inactivity suggests that the rules by which strength is governed by activity are complex or at least different at different synapses.

Several potential explanations for the increased size of EPSPs 
generated in TTX-treated motoneurons may be ruled out. First, it is unlikely that EPSP enhancement represents a compensatory change in the activity level of untreated afferents from synergistic muscles. Walsh et al. (1978) have shown that even with the surgical removal of several of its synergists, homonymous Ia EPSPs generated in motoneurons of the spared MG muscle were not distinguishable from normal ones. It is also unlikely that postsynaptic inactivity induced the increase in EPSP size, as Stein et al. (1980) have shown that central synaptic drive is adequate to maintain motoneuron activity for long periods following complete section of a peripheral nerve. The enhancement of synaptic strength at synapses made with TTX-treated motoneurons must, therefore, be produced by a different mechanism than at the neuromuscular junction (Brown and Ironton, 1977; Snider and Harris, 1979) or stcllate ganglion (Gallcgo and Geijo, 1987) where postsynaptic inactivity was achieved. Postsynaptic changes that could lead to an increase in EPSP size might occur following TTX treatment. Our data do not indicate what the relevant postsynaptic change might have been, but the greater than normal excitability of $\mathrm{MG}$ motoneurons, as judged by a decrease in rheobase current, is evidence for a treatment effect on the postsynaptic cell. In contrast to MG motoneurons, there was no indication of a change in LG-Sol motoneuron properties after TTX treatment of the MG nerve. Elevated EPSP size recorded in $\mathrm{MG}$ motoneurons regardless of rheobase and a tendency toward prolonged rise time were other unique features of records taken from TTX-treated MG motoneurons. These observations suggest that amplification of Ia synaptic strength resulted from different processes when presynaptic versus postsynaptic cells were treated with TTX.

The tendency for EPSPs to be selectively enlarged in lowrheobase cells following the disuse of Ia afferents is consistent with a growing body of evidence that the behavior of these synapses differs depending on certain characteristics of the motoneurons they contact. For example, Mendell and colleagues (Collins et al., 1984, 1986; Koerber and Mendell, 1991) have shown that modulation of EPSP size by high-frequency afferent stimulation varies quantitatively and qualitatively with motoneuron rheobase current. In addition, and particularly noteworthy for the present study, is the earlier demonstration that the enlargement of Ia EPSPs produced by acute spinal transection is exaggerated among motoneurons with the slowest conduction velocities, that is, type $S$ motoneurons (Cope et al., 1980). Findings from the present study, that EPSP enhancement following afferent inactivity is restricted to low-rheobase motoneurons, suggest that the heterogeneous response of Ia-motoneuron synapses to a variety of acute stimuli is a propcrty of those connections that operates when reacting to longer-lasting changes as well.

\section{References}

Bliss TVP, Lomo T (1973) Long-lasting potentiation of synaptic transmission in the dentate area of the anaesthetized rabbit following stimulation of the perforant path. J Physiol (Lond) 232:331-356.

Brown MC, Ironton R (1978) Sprouting and regression of neuromuscular synapses in partially denervated mammalian muscles. J Physiol (Lond) 306:493-510.

Burke RE (1968) Group Ia synaptic input to fast and slow twitch motor units of cat triceps surae. J Physiol (Lond) 196:605-630.

Burke RE (1984) Plasticity in the spinal cord: defining the baseline. In: Development and plasticity of the mammalian spinal cord (Goldberger ME, Gorio A, Murray M, eds), pp 1-12. New York: Springer.

Burke RE, Rymer WZ, Walsh JV (1976) Relative strength of synaptic input from short-latency pathways to motor units of defined type in cat medial gastrocnemius. J Neurophysiol 39:447-458.

Collins WF, Honig MG, Mendell LM (1984) Heterogeneity of group Ia synapses on homonymous alpha-motoneurons as revealed by high frequency stimulation of Ia afferent fibers. J Neurophysiol 52:980993.

Collins WF, Davis BM, Mendell LM (1986) Amplitude modulation of EPSPs in motoneurons in response to a frequency-modulated train in single Ia afferent fibers. J Neurosci 6:1463-1468.

Cope TC, Nelson SG, Mendell LM (1980) Factors outside the neuraxis mediate "acute" increase in EPSP amplitude caudal to spinal cord transection. J Neurophysiol 44:174-183.

Cope TC, Hickman KR, Botterman BR (1988) Acute effects of spinal transection on EPSPs produced by single homonymous Ia-fibers in soleus alpha-motoneurons in the cat. J Neurophysiol 60:1678-1694.

Eccles JC (1964) The physiology of synapses. New York: Springer.

Eccles JC, McIntyre AK (1951) Plasticity in mammalian monosynaptic reflexes. Nature 167:466-468.

Fields RD, Chang Y, Nelson PG (1991) Calcium, network activity, and the role of NMDA channels in synaptic plasticity in vitro. J Neurosci 11:134-146.

Foehring RC, Sypert GW, Munson JB (1986) Properties of self-reinnervated motor units of medial gastrocnemius of cat. II. Axotomized motoneurons and time course of recovery. J Neurophysiol 55:947965.

Gallego R, Geijo E (1987) Chronic block of the ccrvical trunk increases synaptic efficacy in the superior stellate ganglia of the guinea-pig. $J$ Physiol (Lond) 382:449-462.

Gallego R, Kuno M, Nunez R, Snider WD (1979) Disuse enhances synaptic efficacy in spinal motoneurons. J Physiol (Lond) 291:191205.

Hebb DO (1949) The organization of behavior. New York: Wiley.

Koerber HR, Mendell LM (1991) Modulation of synaptic transmission at Ia-afferent fiber connections on motoneurons during high-frequency stimulation: role of postsynaptic target. J Neurophysiol 65:590597.

Levy WB, Steward O (1979) Synapses as associative memory elements in the hippocampal formation. Brain Res 175:233-245.

Lynch GS, Dunwiddie T, Gibkoff V (1977) Heterosynaptic depression: a postsynaptic correlate of long-term potentiation. Nature 266:737739.

Manabe T, Kaneko S, Kuno M (1989) Disuse-induced enhancement of Ia synaptic transmission in spinal motoneurons of the rat. J Neurosci 9:2455-2461.

Mayer RF, Burkc RE, Toop J, Hodgson JA, Kanda K, Walmsley B (1981) The effect of long-term immobilization on the motor unit population of the cat medial gastrocnemius muscle. Neuroscience 6 : 725-739.

Mendell LM (1984) Modifiability of spinal synapses. Physiol Rev 64: 260-324.

Munson JB, Foehring RC, Sypert GW (1985) Nerve block with tetrodotoxin mimics axotomy of cat motoneurons. Soc Neurosci Abstr 11:1145.

Nelson SG, Mendell LM (1979) Enhancement in Ia-motoneuron synaptic transmission caudal to chronic spinal cord transection. J Neurophysiol 42:642-653.

Pinter MJ, Vanden Noven S (1989) Effects of preventing reinnervation on axotomized spinal motoneurons in the cat. I. Motoneuron electrical properties. J Neurophysiol 62:31 1-324.

Rasmussen S, Chan AK, Goslow GE (1978) The cat step cycle: electromyographic patterns for hindlimb muscles during posture and unrestrained locomotion. J Morphol 155:253-270.

Romanes GJ (1951) The motor cell columns of the lumbo-sacral spinal cord of the cat. J Comp Neurol 94:313-363.

Snider WD, Harris GL (1979) A physiological correlate of disuseinduced sprouting at the neuromuscular junction. Nature 281:69-71.

Stanton PK, Sejnowski TJ (1989) Associative long-term depression in the hippocampus induced by Hebbian covariance. Nature 339: 215-218.

Stein RB, Gordon T, Hoffer JA, Davis LA, Charles D (1980) Longterm recordings from cat peripheral nerves during degeneration and regeneration: implications for human nerve repair and prosthetics. In: Nerve repair and regeneration (Jewett DL, McCarroll HR, eds), pp 166-176. St. Louis: CV Mosby. 
Stent GS (1973) A physiological mechanism for Hebb's postulate of learning. Proc Natl Acad Sci USA 70:997-1001.

Tsukahara N, Fujito Y (1981) Neuronal plasticity in the newborn and adult feline red nucleus. In: Lesion-induced neuronal plasticity in sensorimotor system (Flohr H, Precht W, eds), pp 64-74. New York: Springer.

Walsh JV, Burke RE, Rymer WZ, Tsairis P (1978) Effect of compensatory hypertrophy studied in individual motor units in medial gastrocnemius muscle of the cat. J Neurophysiol 41:496-508.
Webb CB, Cope TC (1990) Use-dependent modification of Ia afferent synaptic strength. Soc Neurosci Abstr 16:1163.

Zengel JE, Reid SA, Sypert GW, Munson JB (1985) Membrane electrical properties and prediction of motor-unit type of medial gastrocnemius motoneurons in the cat. J Neurophysiol 53:1323-1344. 